University of Nebraska - Lincoln

DigitalCommons@University of Nebraska - Lincoln

\title{
Patch scale turbulence over dryland and irrigated surfaces in a semi-arid landscape under advective conditions during BEAREX08
}

\author{
J.H. Prueger \\ USDA-ARS, john.prueger@ars.usda.gov
}

J. G. Alfieri

USDA-ARS, joe.alfieri@ars.usda.gov

L.E. Hipps

Utah State University

W.P. Kustas

USDA-ARS

\section{J.L. Chavez \\ Colorado State University}

See next page for additional authors

Follow this and additional works at: https://digitalcommons.unl.edu/usdaarsfacpub

Prueger, J.H.; Alfieri, J. G.; Hipps, L.E.; Kustas, W.P.; Chavez, J.L.; Evett, S.R.; Anderson, M. C.; French, A. N.; Neale, C. M.U.; McKee, L.G.; Hatfield, J. L.; Howell, T. A.; and Agam, Nurit, "Patch scale turbulence over dryland and irrigated surfaces in a semi-arid landscape under advective conditions during BEAREX08" (2012). Publications from USDA-ARS / UNL Faculty. 1171.

https://digitalcommons.unl.edu/usdaarsfacpub/1171

This Article is brought to you for free and open access by the U.S. Department of Agriculture: Agricultural Research Service, Lincoln, Nebraska at DigitalCommons@University of Nebraska - Lincoln. It has been accepted for inclusion in Publications from USDA-ARS / UNL Faculty by an authorized administrator of DigitalCommons@University of Nebraska - Lincoln. 


\section{Authors}

J.H. Prueger, J. G. Alfieri, L.E. Hipps, W.P. Kustas, J.L. Chavez, S.R. Evett, M. C. Anderson, A. N. French, C. M.U. Neale, L.G. McKee, J. L. Hatfield, T. A. Howell, and Nurit Agam 


\title{
Patch scale turbulence over dryland and irrigated surfaces in a semi-arid landscape under advective conditions during BEAREX08 is
}

\author{
J.H. Prueger ${ }^{\text {a,* }}$, J.G. Alfieri ${ }^{\mathrm{b}}$, L.E. Hipps ${ }^{\mathrm{c}}$, W.P. Kustas ${ }^{\mathrm{b}}$, J.L. Chavez $^{\mathrm{g}}$, S.R. Evett ${ }^{\mathrm{d}}$, M.C. Anderson ${ }^{\mathrm{b}}$, \\ A.N. French ${ }^{\text {f }}$, C.M.U. Neale ${ }^{\mathrm{e}}$, L.G. McKee ${ }^{\mathrm{b}}$, J.L. Hatfield ${ }^{\mathrm{a}}$, T.A. Howell ${ }^{\mathrm{d}}$, N. Agam $^{\text {h }}$ \\ ${ }^{a}$ USDA-ARS, National Lab of Agriculture and the Environment, 2110 University Blvd., Ames, IA 50011, USA \\ ${ }^{\mathrm{b}}$ USDA-ARS, Hydrology E Remote Sensing Lab., Bldg. 007, BARC-West, Beltsville, MD 20705, USA \\ ' Plants, Soils E Climate, Utah State University, 4820 Old Main Hill, Logan, UT 84322-4105, USA \\ ${ }^{\mathrm{d}}$ USDA-ARS, Conservation and Production Research Lab., P.O. Drawer 10, Bushland, TX 79012, USA \\ e Bio \& Irrigation Engr., Utah State University, 4105 Old Main Hill, Logan, UT 84322-4105, USA \\ ${ }^{\mathrm{f}}$ USDA-ARS, Arid-Land Agricultural Research Center, 21881 North Cardon Lane, Maricopa, AZ 85238, USA \\ ${ }^{\mathrm{g}}$ Dept. of Civil \& Environ. Engr., Colorado State University, 1372 Campus Delivery, Fort Collins, CO 80523, USA \\ ${ }^{\mathrm{h}}$ Gilat Research Center, Agricultural Research Organization, Rural Delivery Negev 85280, Israel
}

\section{A R T I C L E I N F O}

\section{Article history:}

Available online 28 July 2012

\section{Keywords:}

Surface energy flux

Turbulence

Evapotranspiration

Advection

Eddy covariance

Surface heterogeneity

\begin{abstract}
A B S T R A C T
Quantifying turbulent fluxes of heat and water vapor over heterogeneous surfaces presents unique challenges. For example, in many arid and semi-arid regions, parcels of irrigated cropland are juxtaposed with hot, dry surfaces. Contrasting surface conditions can result in the advection of warm dry air over an irrigated crop surface where it increases the water vapor deficit and, thereby, atmospheric demand. If sufficient water is available, this can significantly enhance evaporative water loss from the irrigated field. The scale and frequency of turbulent eddies over an irrigated surface during periods of strong advection is not fully understood. High frequency $(20 \mathrm{~Hz})$ data were acquired over irrigated cotton, wheat stubble, and rangeland fields during the 2008 growing season as part of the Bushland Evapotranspiration and Agricultural Remote Sensing Experiment (BEAREX08). Spectral analysis of momentum and scalar quantities including heat and water vapor revealed low frequency features in the turbulence structure due to the penetration of the surface boundary layer by large-scale eddies during periods of unusually strong advection. Wavelet analysis was applied to assess specific events contributing to the spatial and temporal structure of turbulent flux eddies. The analysis showed that low frequency contributions were linked to both local and regional scale advective processes. These results clearly point to a need to better understand surface energy balance exchange for heterogeneous surfaces in arid and semi-arid regions under conditions of strong local and regional advection.
\end{abstract}

Published by Elsevier Ltd.

\section{Introduction}

Semi-arid regions account for more than $12 \%$ of the earth's terrestrial surface and support significant human populations and

\footnotetext{
The U.S. Department of Agriculture (USDA) prohibits discrimination in all its programs and activities on the basis of race, color, national origin, age, disability, and where applicable, sex, marital status, familial status, parental status, religion, sexual orientation, genetic information, political beliefs, reprisal, or because all or part of an individual's income is derived from any public assistance program. (Not all prohibited bases apply to all programs.) Persons with disabilities who require alternative means for communication of program information (Braille, large print, audiotape, etc.) should contact USDA's TARGET Center at (202) 720-2600 (voice and TDD). To file a complaint of discrimination, write to USDA, Director, Office of Civil Rights, 1400 Independence Avenue, S.W., Washington, D.C. 20250-9410, or call (800) 795-3272 (voice) or (202) 720-6382 (TDD). USDA is an equal opportunity provider and employer.

* Corresponding author. Address: USDA-ARS, National Lab of Agriculture and the Environment, 2150 University Blvd., Ames, IA 50011, USA.

E-mail address: john.prueger@ars.usda.gov (J.H. Prueger).
}

agricultural production [1]. These regions can support rain-fed or dryland agriculture, however irrigation is frequently required to maximize productivity. The combination of irrigation and modern agricultural practices in semi-arid areas often results in a heterogeneous 'patchwork' of irrigated and dryland (non-irrigated) surfaces that vary significantly in area and vegetative composition. At the patch (field) scale this can result in the development of local boundary layers (stable and unstable) over disparate surfaces resulting in the advection of warm dry air from surrounding parched landscapes to the irrigated cropped surfaces. On larger spatial scales $(>1 \mathrm{~km})$, where multiple irrigated fields are interspersed among non-irrigated fields, regional advection can be superimposed atop the local advection [2]. Regardless of the scale, the resulting increase in atmospheric demand over the irrigated crops can enhance evaporative water loss if sufficient water is available [3].

Monin-Obukhov similarity theory (MOST) [4] has been widely used to study the turbulent exchange of mass and energy in the 
surface boundary layer (SBL) over homogeneous surfaces [5]. The application of MOST to heterogeneous landscapes in semi-arid regions has proven more challenging because some of the underlying assumptions for MOST such as extensive homogeneous upwind fetch are not appropriate for these surfaces. Correspondingly, there have been numerous studies in recent years documenting apparent inconsistencies between the observed turbulent structure of the SBL and those predicted by MOST [6-15]. Large scale eddies can develop as a result of diverse phenomena such as shearing motions in a neutral boundary layer [16-18], topographically induced motions in a stable SBL [19], and convective motions associated with the outer layer of the convective boundary layer $[6,9,12,14]$. Regardless of their origin, large eddies are capable of penetrating the SBL and significantly altering the turbulence structure $[6,7,14]$. These disturbances in the SBL not only affect the partitioning of surface energy fluxes, but also have unique spectral signatures that deviate significantly from those predicted by MOST $[2,9,12,19-25]$.

Accurate measurements of turbulent fluxes of heat and water over vegetated land surfaces are critical for a broad range of activities including hydrological studies, validation of model and remote sensing-based estimates of regional scale evapotranspiration (ET), and irrigation management [3,26-28]. Advection can alter the partitioning of the surface energy budget and complicate the interpretation of turbulent flux measurements; consequently, the response of land-atmosphere exchange to intense advective conditions over irrigated surfaces is not fully understood. The objective of this paper is to investigate spectral signatures of turbulent eddies, especially low frequency turbulence contributing to local and regional advection that modifies the surface exchange of heat and moisture. Using data collected at the USDA-ARS Conservation and Production Research Laboratory (CPRL) in Bushland, Texas as a part of the 2008 Bushland Evapotranspiration and Agricultural Remote Sensing Experiment (BEAREX08; see Evett et al., this issue), this study examines the spectral response to strongly - wind speeds exceeded $7 \mathrm{~m} \mathrm{~s}^{-1}$ - advective conditions in a region characterized by a 'patchwork' of dryland and irrigated fields. Specifically, a spectral analysis of the turbulent transport of momentum, heat, and water vapor was conducted while focusing on a period when soil water was not limiting and advection was clearly present. Studying turbulent flux exchanges in this environment lends itself to evaluating the impact on surface layer turbulent structures by local and regional scale advection.

\section{BEAREX 2008 experiment}

BEAREX08 was conducted jointly by federal, state, and university researchers to investigate temporal and spatial variations of the surface energy balance in a semi-arid region. The study was conducted from early June through mid-August 2008 in the High Plains of the Texas Panhandle at the USDA-ARS Conservation and Production Research Laboratory (CPRL) near Bushland, Texas $\left(35.183^{\circ} \mathrm{N}, 102.100^{\circ} \mathrm{W}, 1170 \mathrm{~m}, \mathrm{ASL}\right)$. The work presented here focused on data collected on August 4 during the period from 1600 to 1700 CST at two of the BEARX08 sites. The first site was a $220 \times 220 \mathrm{~m}$ cotton field irrigated with a lateral-move sprinkler irrigation system (referred to as IC hereafter). The second was a large winter wheat field located directly south and adjacent to the IC (referred to as WW hereafter) that had been harvested prior to the field campaign so that only dry stubble residue remained. An analysis using data from a rangeland site (referred to as RL hereafter) located approximately $1 \mathrm{~km}$ south east of the IC and WW is also presented herein. Both the WW and the RL sites were dormant and extremely dry due to persistent drought conditions. Thus, they were significant sources of sensible heat, especially during after- noon periods. The juxtaposition of these fields (Fig. 1) yielded the ideal configuration for measuring and evaluating sensible $(H)$ and latent $(\lambda E)$ heat fluxes over dry and wet surfaces during periods of strong advection.

August 4, 2008 was selected for this analysis because it represents a typical day during the growing season in the Texas panhandle. On this day, as with many others during the field campaign, the region was dominated by an anticyclonic (high pressure) system characterized by high temperatures and moderate to strong southerly and south westerly winds (3-8 $\mathrm{m} \mathrm{s}^{-1}$ ) and strongly advective conditions. The presence of strong advection was confirmed by large negative, i.e. downward-directed, $H$ $\left(>-100 \mathrm{~W} \mathrm{~m}^{-2}\right)$.

\section{Instrumentation}

\subsection{Surface energy balance measurements}

The three fields were each instrumented with an eddy covariance surface energy balance system (ECSEB) comprised of a sonic anemometer (CSAT- $3,{ }^{1}$ Campbell Scientific Inc., Logan, UT) to measure the orthogonal wind velocity components and a fast response open-path infrared gas analyzer (Li-7500, Li-COR Biosciences, Lincoln, Nebraska) to measure water vapor and carbon dioxide concentrations. Both instruments were mounted at a height of $2.25 \mathrm{~m}$ above ground level (AGL) and oriented due south.

Fast response $(20 \mathrm{~Hz})$ air temperature $(T)$ was measured with a fine-wire thermocouple (FW05, Campbell Scientific). Net radiation $\left(R_{n}\right)$ was measured with a four-component net radiometer (CNR-1, Kipp and Zonen, Delft, The Netherlands) that measures incident and upwelling short and long wave radiant energy. Soil heat flux $(G)$ was measured using three soil heat flux plates (HFT-3, Radiation Energy Balance Systems, Bellevue, Washington). Each heat flux plate was co-located with a pair of Type-T soil thermocouples (Omega Engineering, Inc. Stamford, Connecticut) and a coaxial impedance dielectric reflectometry soil moisture probe (Stevens Hydra Probe, Portland, OR). The soil heat flux plates were installed at a depth of $0.08 \mathrm{~m}$ with soil thermocouples located at 0.02 and $0.06 \mathrm{~m}$ directly above each heat flux plate. The soil moisture sensor was buried at a depth of $0.05 \mathrm{~m}$ adjacent to the heat flux plates. The soil temperature and moisture measurements were used to calculate heat storage in the overlying soil to adjust $G$ at the surface. Ancillary measurements included air temperature and relative humidity measured with a combined humidity and temperature sensor (HMP45C, Vaisala, Helsinki, Finland), surface radiometric temperature $\left(T_{s f c}\right)$ with a nadir view infrared radiometer (SI111, Apogee, Logan, UT) and a tipping bucket rain gauge all at a height of $2.25 \mathrm{~m}$ AGL.

The sampling rate was $20 \mathrm{~Hz}$ for the EC measurements and $0.1 \mathrm{~Hz}$ for the slow response instruments except the soil moisture sensor. The soil moisture measurements were made once at the top of every hour. The $20 \mathrm{~Hz}$ data were stored on compact flash cards; the slow response measurements were stored as 15 min averages on Campbell Scientific CR5000 data loggers.

Hourly fluxes of $H$ and $\lambda E$ were computed using standard postprocessing procedures that included a two-dimensional coordinate rotation [29] to align the $u$ wind velocity component with the direction of the mean stream flow, corrections for frequency response attenuation, separation distance between the sonic anemometer and infrared gas analyzer [30], and buoyancy effects on

\footnotetext{
1 The use of trade, firm, or corporate names in this article is for the information and convenience of the reader. Such use does not constitute an official endorsement or approval by the U.S. Department of Agriculture or the Agricultural Research Service of any product or service to the exclusion of others that may be suitable.
} 




Fig. 1. Landsat image of Bushland, Texas, cotton and wheat field sites and eddy covariance surface energy balance system (ECSEBS).

the vertical fluxes due to water vapor density and temperature fluctuations [31].

\section{Data processing}

\subsection{Ogive}

A recurring issue when computing surface turbulent fluxes using eddy covariance measurements is the determination of an appropriate averaging period $[11,21,32,35]$. Under the assumption that all of the contributing eddies are sampled and no additional information can be acquired by extending the measurement period, a 30-min averaging length has typically been used over large spatially-uniform vegetated surfaces. While this assumption is typically appropriate for homogeneous surfaces, it might not be valid for many heterogeneous environments including irrigated semiarid landscapes where advective enhancement of evaporation is always a possibility [23].

The ogive function was used to determine both the relative contribution of eddies of differing sizes and necessary averaging period to capture the contribution of all eddy sizes to the cumulative flux $[5,33,34]$. Mathematically, the ogive is the cumulative integral of the co-spectrum of interest $\left(w T, w \rho_{v}\right.$, $u w$, etc.) spanning all frequencies for the measurement period:

$O g_{w, j}(f)=\int_{\infty}^{f_{0}} C_{w, j}(f) d f$

where $\mathrm{Co}_{w, j}$ is the co-spectrum $w$ and $j$, which can be either another wind velocity component or scalar quantity, and $f$ is frequency. The ogive and co-spectrum contain the same information; the main advantage of an ogive is that it can be used to determine whether an averaging period is sufficiently long to sample all contributing eddies by observing when an ogive has reached an asymptote. The ogive can also be useful to visually identify whether large turbulent eddies have disturbed the local SBL. Counter-gradient contributions to a flux caused by large scale eddy intrusions into the SBL result in clear departures from typically observed smooth sigmoid shapes of an ogive.

\subsection{Calculation of spectra and cospectra}

Power spectra and co-spectra were computed using $20 \mathrm{~Hz}$ EC measurements for the orthogonal wind velocities, $\rho_{\nu}$, and $T$ measured with a fine-wire thermocouple. Prior to calculating the spectra, the 71,992 measurements collected for each quantity during the full hourly period (the acquisition of $20 \mathrm{~Hz}$ data was suspended during the last $0.4 \mathrm{~s}$ of each hour to allow for the measurement of soil moisture) were conditioned as follows: (i) the velocity and scalar data were corrected to adjust for the temporal offset in the measurements of the wind velocity components and those of the scalar quantities, (ii) linear trends were removed, (iii) nonphysical values and statistical outliers were identified and replaced using the algorithm developed by Højstrup [34]. Next, the fast Fourier algorithm was used to compute the Fourier transform of each quantity. After discarding the redundant negative harmonics, the real and imaginary components were combined in the standard way to produce power spectra and co-spectra $[48,49]$. The resulting spectra were smoothed using a Daniel window that preserves 
the total variance or covariance. Finally, the spectra were normalized by the quotient of frequency and the square of the appropriate characteristic scale. The power spectra and co-spectra were plotted on semi-log scale against frequency scaled by the quotient of the measurement height and mean wind speed.

The characteristic velocity, i.e. friction velocity $\left(u_{*}\right)$, temperature $\left(\theta_{*}\right)$ and humidity $\left(\rho_{v_{*}}\right)$ scales were computed, respectively, as:

$u_{*}=\left({\overline{u^{\prime} W^{\prime}}}^{2}+{\overline{v^{\prime} W^{\prime}}}^{2}\right)^{0.25}$

$\theta_{*}=\overline{w^{\prime} T^{\prime}} / u_{*}$

$\rho_{v *}=\overline{w^{\prime} \rho_{v}^{\prime}} / u_{*}$

where primes denote instantaneous deviations from the mean and paired quantities with overbars are time averaged covariances.

\subsection{Calculation of surface layer stability}

The surface layer stability was evaluated in terms of the stability parameter $(\zeta)$, which is defined as the ratio of the measurement height $z(\mathrm{~m})$ and the Monin-Obukhov length $(L)$. This length scale was calculated following Businger and Yaglom [4,36]:

$L=\frac{-u_{*}^{3} \rho}{k g\left[\frac{H}{T_{K} C_{p}}+0.61 \frac{\lambda E}{\lambda_{v}}\right]}$

where $k$ is the dimensionless Von Karman's constant $(0.40), g$ is acceleration due to gravity $\left(9.81 \mathrm{~m} \mathrm{~s}^{-2}\right), T_{K}$ is the mean air temperature $(\mathrm{K}), C_{p}$ is the specific heat of moist air $\left(\mathrm{J} \mathrm{kg}^{-1} \mathrm{~K}^{-1}\right), \rho$ is density of air $\left(\mathrm{kg} \mathrm{m}^{-3}\right), \lambda_{v}$ is the latent heat of vaporization $\left(\mathrm{J} \mathrm{kg}^{-1}\right)$, and the remaining variables are defined above.

\subsection{Calculation of wavelets}

Wavelet analysis provides a robust method for analyzing the spectral characteristics of turbulent processes including the exchange of heat and moisture between the land surface and atmosphere. In contrast to conventional Fourier analysis techniques which assumes a stationary process and produces time-averaged results, wavelet analysis is able to transform time series information into a two-dimensional time-frequency domain. As a result, wavelet analysis allows the evolution of different frequency contributions to the time series to be evaluated and the effects of temporally localized events to be identified. Although numerous detailed discussions of wavelet analysis and its application to turbulent processes are available, e.g. [37-44], a brief description is provided here. Just as conventional spectral analysis relies on the Fourier transform, wavelet analysis utilizes the wavelet transform, the convolution of the temporal data $(g(t))$ with an appropriate wavelet function $(\psi(t))$ :

$W(a, \tau)=\frac{1}{a} \int g(t) \psi\left(\frac{t-\tau}{a}\right) \partial t$

where $W(a, \tau)$ is the wavelet transform, $t$ is time, $a$ is the scale dilation parameter, $\tau$ is the translation parameter, and all other terms are previously defined. The wavelet function can be either real or complex, but it must fulfill several criteria: (i) it must have a mean of zero, (ii) it must be localized in both the time and frequency domains, and (iii) it should mimic the features of $g(t)$ [41]. In this analysis, the Morlet wavelet function was used; this wavelet function has also been used in a number of other recent studies [41-43]. The parameter $\tau$ indicates the position of $\psi(t)$ relative to $g(t)$. The parameter $a$ is a scaling factor that either contracts or dilates the length of $\psi(t)$, which allows the role of differing frequencies to be evaluated. The relationship between $a$ and frequency $(f)$ is:

$f=\frac{s f_{c}}{a}$

where $s$ is the sampling rate and $f_{c}$ is the center frequency of $\psi(t)$. Additionally, $W(a, \tau)$ can be treated analogously to the Fourier transform to produce a two-dimensional representation of the power spectrum or co-spectrum, referred to as a scalogram, in the timefrequency domain according to:

$\chi_{x}(a, \tau)=W_{x}(a, \tau) W_{x}^{*}(a, \tau)$

$\chi_{x y}(a, \tau)=W_{x}(a, \tau) W_{y}^{*}(a, \tau)$

where $\chi_{x}$ represents the wavelet-based counterpart of the power spectrum for quantity $x, \chi_{x y}$ represents the scalogram equivalent to the co-spectrum of quantities $x$ and $y$, and the superscript asterisks denotes the complex conjugate. By integrating each $\chi_{x}$ associated with a given $a$, or equivalently $f$, with respect to time, a wavelet-based power spectrum corresponding to the conventional Fourier transform-based power spectrum can be generated. Similarly, by integrating each $\chi_{x y}$ associated with a given $a$, or equivalently $f$, with respect to time, a wavelet-based power co-spectrum corresponding to the conventional Fourier transform-based cospectrum can be generated [45]. Moreover, by integrating $\chi_{x}$ or $\chi_{x y}$ at each $t$ with respect to $a$, the change in power over time can be evaluated. Additionally, in order to allow direct comparisons of the wavelet-based spectra with the conventional spectra, $f$ is scaled by $z U^{-1}$ and $\chi$ is scaled by $f s_{*}^{-2}$ where $z$ is the measurement height, $U$ is the wind speed, and $s_{*}$ is the characteristic scale associated with the scalar quantity $s$.

\section{Results and discussion}

\subsection{General surface layer conditions}

The diurnal surface and near-surface atmospheric conditions on August 4, 2008 for the IC and WW are shown in Fig. 2a-h. Mean hourly wind direction ranged between $171^{\circ}$ and $228^{\circ}$ over the course of the day and was nearly due south $\left(194^{\circ}\right)$ from 1600 to 1700 CST (Fig. 2a). Mean wind speeds were slightly lower over the IC compared to the WW site (Fig. 2b). This likely was due to larger roughness elements of the IC, where the mean height of the cotton was approximately $0.60 \mathrm{~m}$, compared with the $0.15 \mathrm{~m}$ height of the wheat stubble. Friction velocity over the cotton canopy was on average $0.1 \mathrm{~m} \mathrm{~s}^{-1}$ greater than over the WW (Fig. 2c). During the day, mean hourly air $T$ and $T_{s f c}$ were larger in the WW than the IC. At mid-day the difference in $T$ between the two fields was approximately $2{ }^{\circ} \mathrm{C}$ while during the period from 1600 to 1700 CST it was approximately $3{ }^{\circ} \mathrm{C}$ (Fig. 2e). The difference in $T_{s f c}$ was even more striking with $T_{s f c}$ for the WW exceeding that of the IC by as much as $23^{\circ} \mathrm{C}$ (Fig. 2f). This too was not unexpected given both the greater soil moisture content in the IC (Fig. $2 \mathrm{~h}$ ) and the capacity for the cotton to cool the surface through transpiration and shading.

The result of the temperature differences between the IC and WW was the development of distinct local stability regimes in fields that were separated by mere meters. During the day, the stability parameter $(\zeta)$ for the WW was negative indicating unstable conditions due to substantial convective buoyancy (Fig. 2d). In contrast, $\zeta$ over the cotton field was consistently positive, indicating stable conditions for the entire diurnal cycle. For the period of interest in this study (1600-1700 CST) the stability parameter for the IC was approximately 0.02 compared to -0.06 for the WW. Stated differently, the IC had a shallow locally-derived stable bound- 

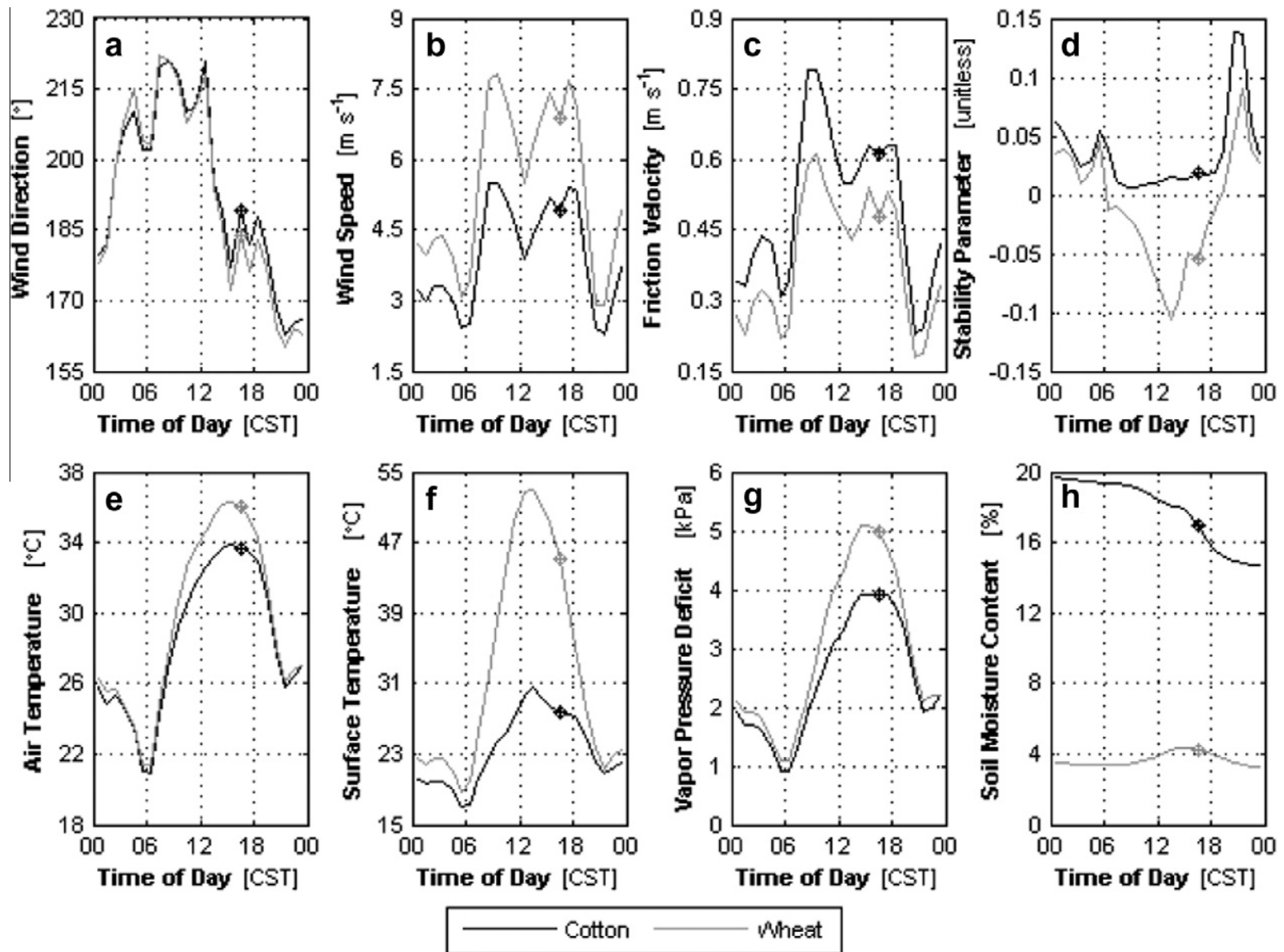

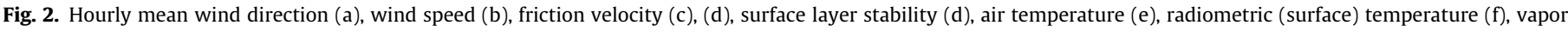

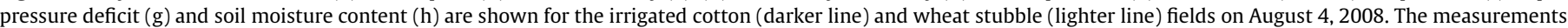
for the period from 1600 to 1700 CST are indicated by the cross-hairs.

ary layer. In contrast, the boundary layer of the WW, which was characterized by quasi-normal unstable conditions, represented a significant source of vapor pressure deficit (Fig. $2 \mathrm{~g}$ ) that was advected with the mean wind over the cotton field.

\subsection{Surface energy balance partitioning}

Hourly means of the surface energy budget components $\left(R_{n}, G\right.$, $H, \lambda E$ ) collected on August 4, 2008 over the IC and WW are presented in Fig. 3a and b. Significant differences in surface conditions between the fields were reflected in the magnitude and partitioning of these fluxes. For example, $R_{n}$ over cotton exceeded that over the WW by as much as $120 \mathrm{~W} \mathrm{~m}^{-2}$, or nearly $20 \%$, during the midday period as a result of lower albedo and cooler surface temperatures. The soil heat flux more clearly demonstrated the role of local surface conditions, such as canopy and row structure, in regulating energy partitioning. This can be seen by comparing the diurnal plot of $G$ over the IC with the time trace for $G$ at the WW. The flux in the WW shows a smooth shape with peak values occurring in the shortly after solar noon. In contrast, the time trace of $G$ measured in the IC is not as smoothly defined and does not reach its peak until approximately 1500 CST. This was due to row orientation and canopy cover. Peak values of $G$ for the IC and WW were similar with $G$ in the WW being slightly greater. While it may be expected that $G$ in the WW would be substantially larger than in the IC given the significantly greater $T_{s f c}$ in the WW (Fig. 2f), this can be explained in terms of differing soil moisture contents, thermal conductivity and thermal inertia at the two sites [45-47]. Soils at both sites were Pullman clay and thus had the same physical characteristics excluding soil water content. The volumetric soil water content of the IC was significantly greater than at the WW ( 0.18 vs. $0.04 \mathrm{~m}^{3} \mathrm{~m}^{-3}$, respectively) on August 4 . Greater soil moisture increases thermal conductivity but lowers thermal inertia resulting in similar $G$ values for the IC and WW sites [46].

Between the hours of 1000 and 1600 CST significant differences in soil water content at the two sites caused $\lambda E$ at the IC to be $12-$ 60 times greater than the flux at the WW (Fig. 3a and b). Additionally, $\lambda E$ over the IC exceeded $60 \mathrm{~W} \mathrm{~m}^{-2}$ during the overnight period. This can be explained by the advection of saturation deficit as observed by the negative $H$ present throughout the whole of August 4. During the day, $H$ at the IC averaged near $-100 \mathrm{~W} \mathrm{~m}^{-2}$ with a peak flux $\left(-153 \mathrm{~W} \mathrm{~m}^{-2}\right)$ occurring near $1800 \mathrm{CST}$. The additional energy from the advection combined with a well watered surface resulted in evapotranspiration rates that exceeded the available energy in the early morning and late afternoon periods (Fig 3a). The sensible heat flux from the WW exhibited a more typical diurnal pattern. During the day, $H$ was positive (upward directed) with peak values approaching $300 \mathrm{~W} \mathrm{~m}^{-2}$ (Fig. 3b) indicating that thermal buoyancy forces were greater than the mechanically driven advective forces. During the overnight period, $H$ was negative (downward directed).

\subsection{Indications of low frequency eddies}

Velocity components for the IC (Fig. 4a-c, stable) and WW (Fig. 4d-f, unstable) for the period from 1600 to 1700 CST are presented as one and thirty-second average raw time series. These averaging periods are shown in lieu of the high frequency 

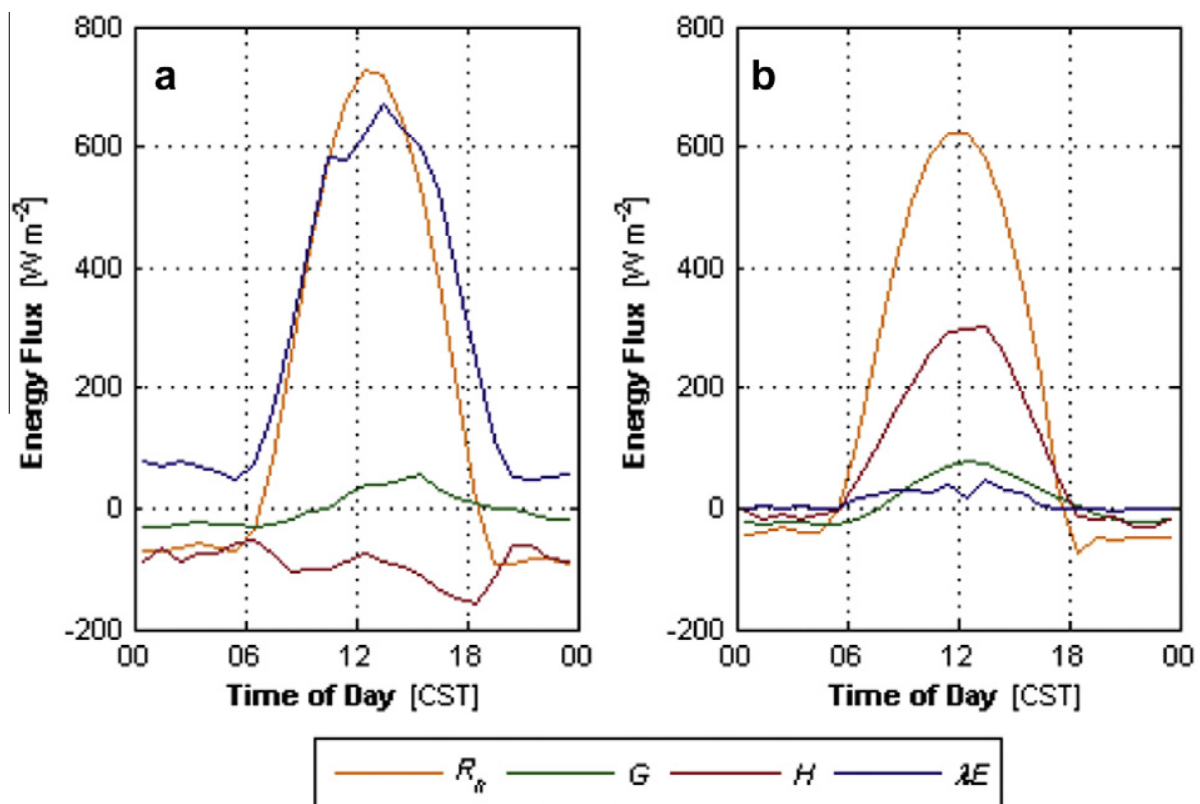

Fig. 3. Diurnal surface energy balance components ( $R n, G, L E, H)$ collected over cotton (a) and wheat stubble (b) on August 4, 2008.


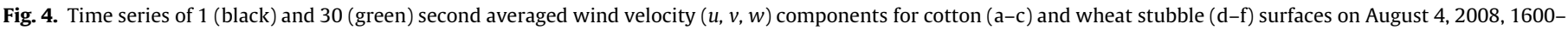
1700 CST. (For interpretation of the references to colour in this figure legend, the reader is referred to the web version of this article.) 
$(20 \mathrm{~Hz})$ data to provide a clearer view of turbulent structures. Both horizontal components ( $u$ and $v$ ) exhibited well-organized and distinct turbulent features across a broad range of scales. These time traces clearly show small scale eddies as well as the presence of low frequency, large-scale eddies under stable and unstable conditions similar to results shown by Massman [30]. Assuming Taylor's hypothesis, estimates of the eddy scales were calculated and were found to range between $2 \mathrm{~m}$ and $>3 \mathrm{~km}$. Greater velocities in $u$ and $v$ were observed in the WW (Fig. 4d and e) relative to the IC (Fig. 4a and b) as a result of lower roughness elements at the WW. Additionally, distinct ramp-like structures can also be observed, suggesting that the surface was well coupled to the SBL. Structures in $u$ and $v$ appear more distinct and better organized over the WW than over the IC. This was attributed to increased high frequency turbulence generated by the IC canopy breaking down some of the larger eddies as they transition from a relatively smooth surface of the WW to the rougher surface of the cotton canopy. As would be expected, vertical velocity $(w)$ showed a less pronounced frequency structure since perturbations in $w$ were absorbed and distorted by the physical ground surface and canopy elements. Larger intermittent $w$ velocities were observed over the IC relative to the $\mathrm{WW}$ as a result of increased surface roughness.

Fig. 5 shows the time series plots for $T$ and $\rho_{v}$ measurements for the IC (Fig. 5a and b) and WW (Fig. 5c and d) during the same period. In contrast to the plot of $T$ for the WW, the time trace of $T$ for the IC shows low frequency oscillations similar to those observed in $u$ (Fig. 4a). This suggests that warm air was transported horizontally along the mean wind direction to the upwind IC. A likely upwind source for this warm air is convectively heated air from the WW where surface temperatures approached $45^{\circ} \mathrm{C}$ (Fig. 2e). Substantially greater perturbations in the magnitude of $T$ were observed over the WW as a result of large $H$ and $T_{s f c}$ associated with that field. Water vapor density concentrations (Fig. 5b-d) also showed differences as a result of differences in the soil water content in the two fields. Fig. 5b show greater high frequency variations in $\rho_{v}$ resulting from interactions of advection transporting warmer drier air to the wetter transpiring and evaporating IC surface. The time series trace for $\rho_{v}$ at the IC site was less apparent but similar to $T$ in Fig. 5a indicating that the two distinct surfaces were well coupled, that is to say high frequency oscillations in $T$ over the WW were reflected with similar high frequency oscillations in $\rho_{v}$ in the IC. The $\rho_{v}$ (Fig. 5d) time trace for the WW clearly showed distinct low frequency variations but little high frequency variation.

\subsection{Ogive comparisons}

Fig. 6 shows the ogive results for $T \rho_{v}, w T, w \rho_{v}$, and $u w$ for the IC (Fig. 6a-d) and WW (Fig. 6e-h). During strongly advective conditions, significant deviations from the typically smooth sigmoid shape normally observed with turbulent fluxes over homogenous surfaces were apparent. Fig. 6a and e represents the ogive for the covariance of $T$ and $\rho_{v}\left(T \rho_{v}\right)$ at the IC and WW respectively. The ogive for the IC showed a gradual accumulation of anti-correlated $T$ and $\rho_{\nu}$ beginning at the highest frequency and continuing until about $0.02 \mathrm{~Hz}$. This is consistent with results from Fig. 3a showing sensible heat flux directed toward the surface and $\lambda E$ moving away from the surface. The high frequency region $(0.2-10 \mathrm{~Hz})$ of the spectra was influenced by the effects of friction (small scale turbulence) with the canopy and ground surface; this is commonly referred to as inner-layer-scaling [6,9,20]. At about $0.02 \mathrm{~Hz}$, an abrupt discontinuity was observed where the transport of $T$ and $\rho_{v}$ were for a brief period positively correlated. This is interpreted to represent the interaction boundary between small eddies associated with the inner layer scaling and larger eddies associated with regional scale convective boundary motions of advection (outer-layer scaling). Fig. 6e shows the ogive plot for the WW, which resembles the expected sigmoid shape and shows an abrupt discontinuity occurring at the same frequency as in the IC.

The surface boundary layer is commonly defined as the lowest $10 \%$ of the convective boundary layer (CBL). Alternatively the Monin-Obukhov Length $(L)$ is defined as the depth of the atmosphere where mechanical mixing dominates over buoyant turbulence; it is equivalent to the depth of the SBL (zsfc) [50-52]. The location of discontinuity, which was found in all of the ogive plots, can be related to the maximum eddy scale within the CBL estimated as
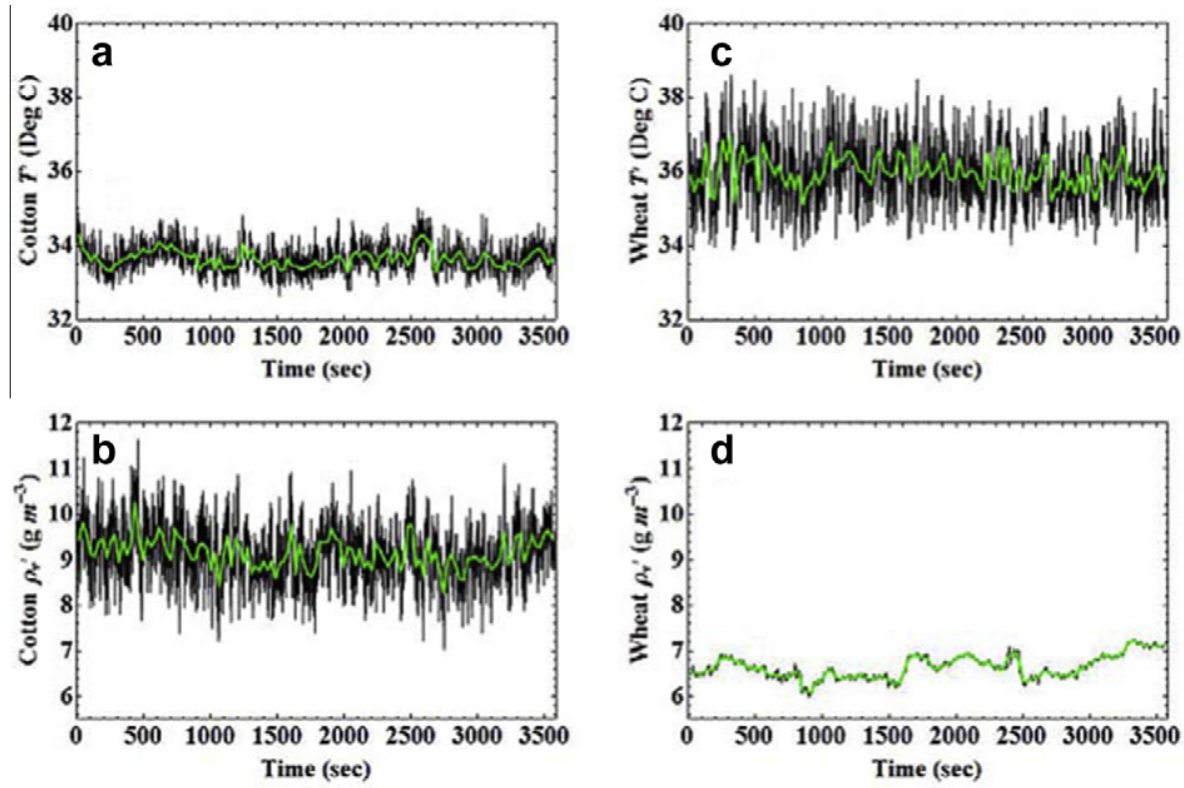

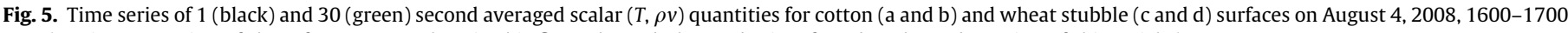
CST. (For interpretation of the references to colour in this figure legend, the reader is referred to the web version of this article.) 

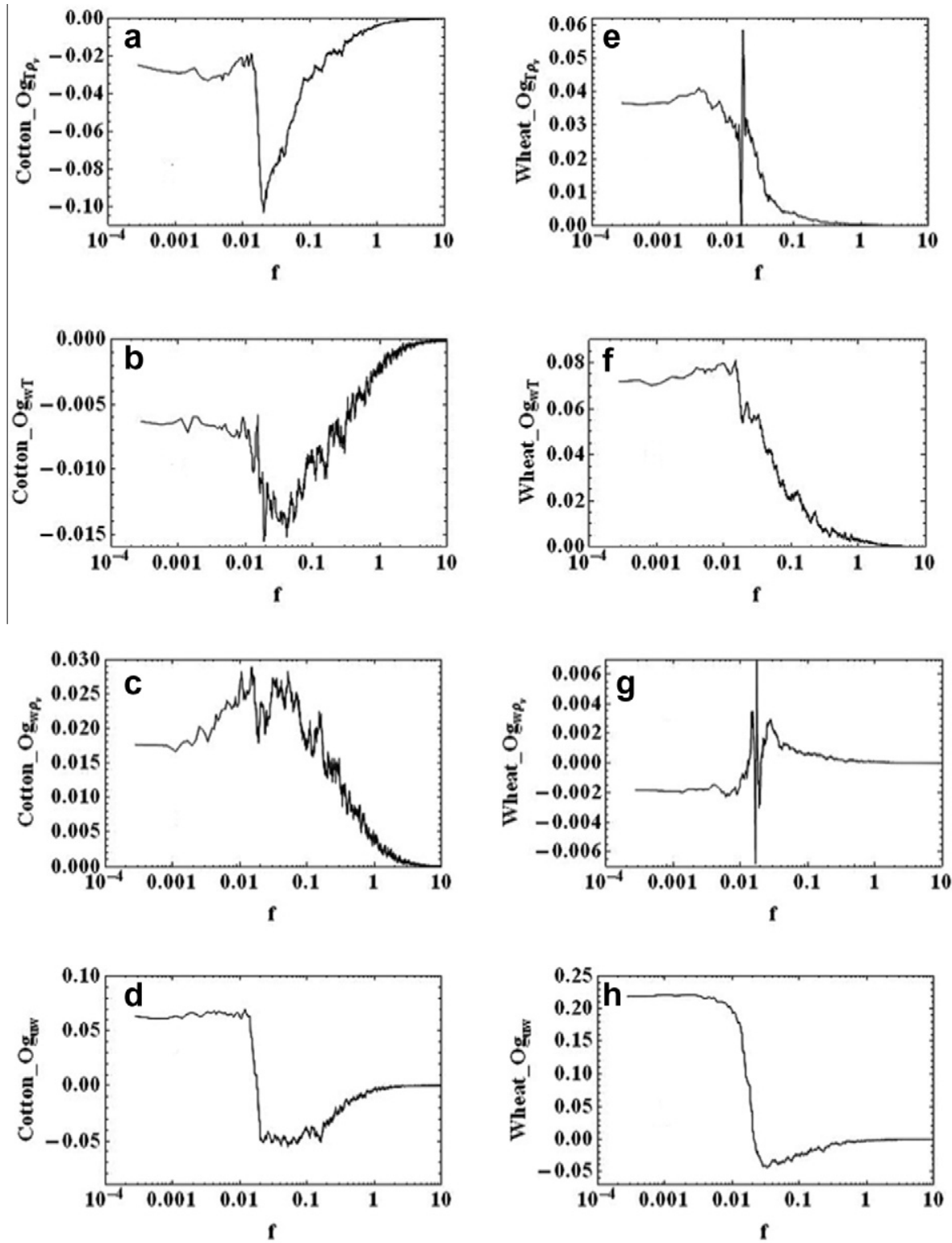

Fig. 6. Cumulative flux (ogive) results for $T \rho v, w T, w \rho v$ and $u w$ for cotton (a-d) and wheat stubble (e-h) surfaces on August 4, 2008, 1600-1700 CST.

$10 L$ [51]. The shape of this ogive is consistent with $T$ and $\rho_{v}$ correlated over a strong convective surface. Low evaporation rates (Fig. 3b) were correlated with large convective vertical motions of $T$ from the parched WW surface.

In all cases $\left(T \rho_{v}, w T, w \rho_{v}\right.$, and $\left.u w\right)$ the ogive plots clearly showed periodic reverse-sign contributions to the cumulative fluxes as well as an abrupt and in some cases a large discontinuity occurring between 0.01 and $0.03 \mathrm{~Hz}$. Assuming that Taylor's hypothesis is valid under these conditions, the abrupt transitional feature occurring in the range of $0.01-0.03 \mathrm{~Hz}$ corresponds to eddies with diameters on the order of $150-500 \mathrm{~m}$ that contribute to the covariance information but were decoupled from the local surface. The contribution of these eddies are associated with outer-layer scaling and represent surfaces that are well outside of the expected footprint of the ECSEB systems.

A comparison of the ogive plots for $w T$ for the IC and WW revealed a strong contrast in the contributions of different eddy scales to $H$ (Fig. 3b and f). Over the IC, both high and low frequency contributions to the flux were generally directed downward toward the surface, but careful examination shows brief periodic po- sitive contributions to $H$. Particularly for frequencies less than $0.04 \mathrm{~Hz}$, the contributions to $w T$ associated with large convective motions tended to positive. Nonetheless, the overall cumulative $w T$ was negative consistent with results shown in Fig. 3a. In contrast, the results for the WW (Fig. 6f) showed that contributions of most frequencies were directed upward and away from the surface. But, as was also seen in Fig. 6b, counter gradient transport can also be observed over the WW indicating that large scale motions affect the WW as well as the IC. The ogive plots for $w \rho_{v}$ at the two fields are likewise distinct. In this case, however, the greatest difference was in the magnitude of the variations of contributions to $\lambda E$. Because the IC (Fig. 6c) represented a well-watered, strongly evaporating surface, the magnitude of the variation for the IC was larger than in the WW. The ogive plots for $u w$ have a similar shape, but the magnitude of the variations in the contributions to the momentum flux were lower by an order of magnitude for the IC field when compared to the WW. This may be due to the local advection of convectively-heated air from the WW to the IC. The heating of air at the WW surface would tend to enhance variations in $w$ while the entrainment of that same air into the surface bound- 

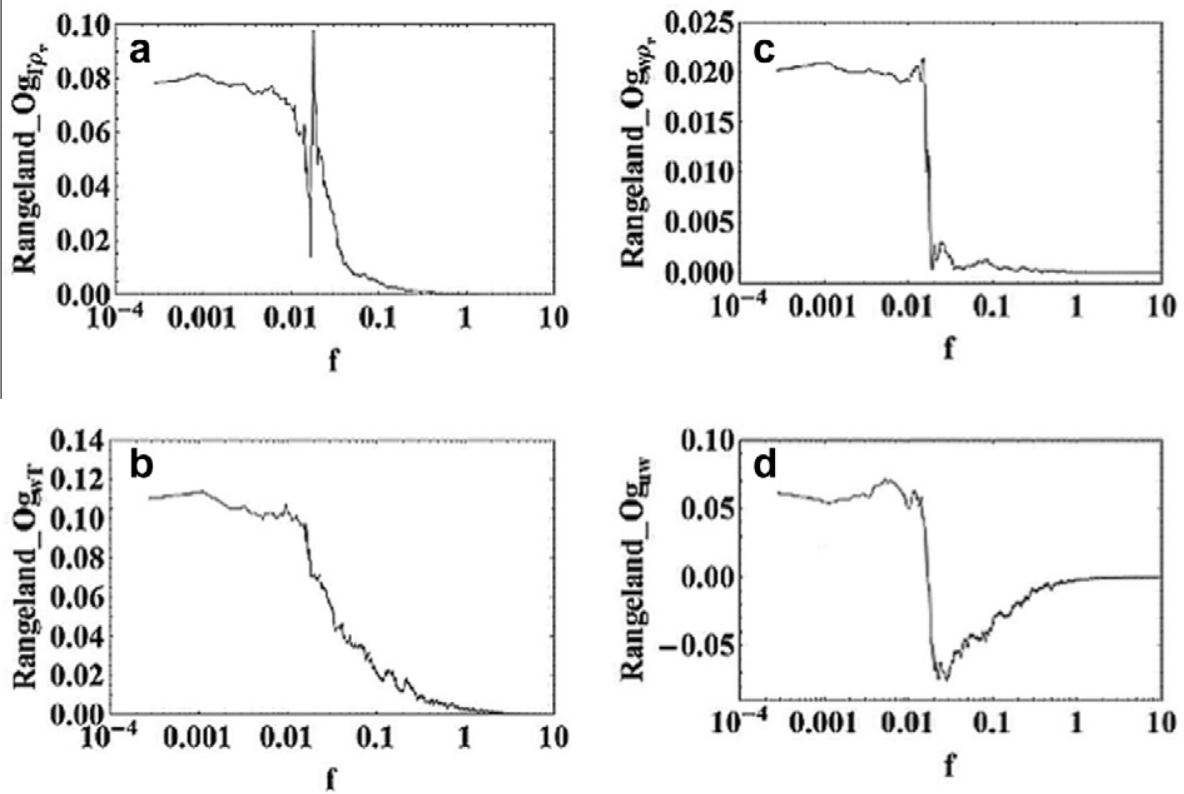

Fig. 7. Cumulative flux (ogive) results for $T \rho v, w T, w \rho v$ and $u w$ for the rangeland surface on August 4, 2008, 1600-1700 CST.

ary layer over the IC would tend to inhibit the upward transport of air by inducing stable conditions. In all cases, the ogive plots indicated the maximum cumulatively integrated fluxes at both fields were obtained at approximately $55 \mathrm{~min}$. Based on these results, an averaging period of $1 \mathrm{~h}$ was used to calculate the turbulent fluxes shown in Fig. 3a and b.
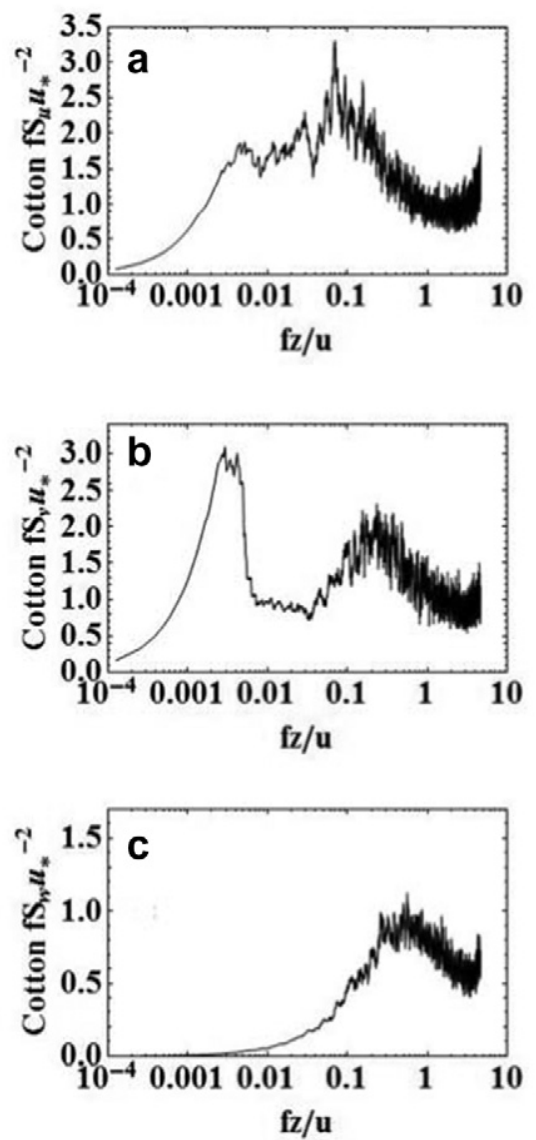

As a final note to the ogive results, an additional series of ogive plots (Fig. 7) were generated for the dormant rangeland site. Comparing Figs. 6 and 7, it can be easily seen that the ogive plots for RL are nearly identical to those from the WW even though the two sites were separated by more than a kilometer. For example, note the clear discontinuity that occurs at frequencies near 0.01 and
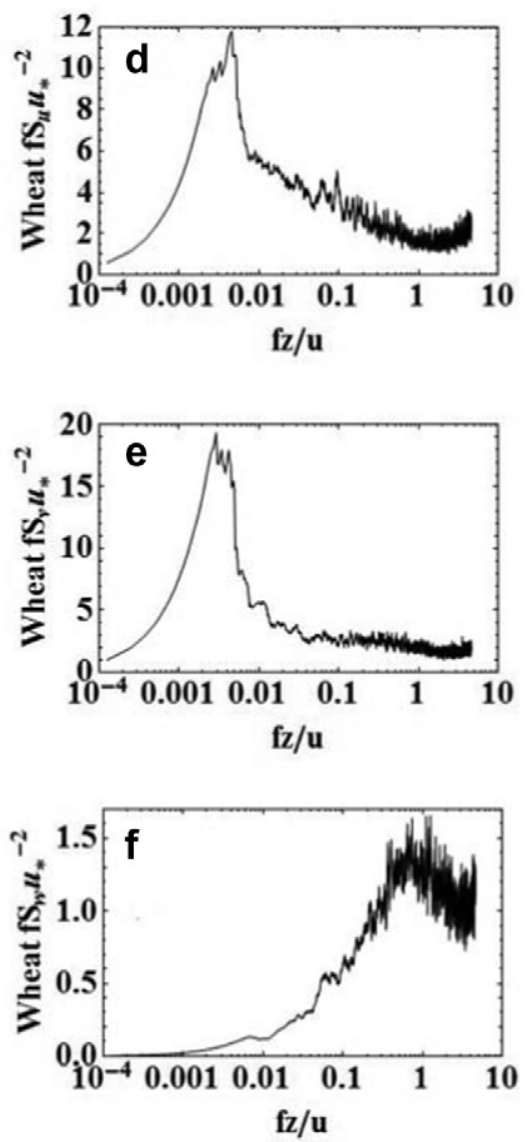

Fig. 8. Power spectra of velocity components $(u, v, w)$ for cotton (a-c) and wheat stubble (d-f) surfaces on August 4, 2008, 1600-1700 CST. 
$0.02 \mathrm{~Hz}$. This indicates that large diameter, low frequency eddies affecting the juxtaposed IC and WW were not only temporally persistent but had a large spatial extent as well.

\subsection{Power spectra of wind velocity components}

Power spectra were calculated for each wind velocity component over the IC and WW during the one-hour period from 1600 to 1700 CST on August 4 (Fig. 8a-f). A comparison of the spectra of the $u$ wind velocity component shows significant variance at low frequencies at both fields (Fig. 8a and d). The magnitude of the low frequency peak at the WW, located at approximately $0.01 \mathrm{~Hz}$, was nearly twice that of the same peak over the IC $\left(f z U^{-1}=0.03\right.$ and 0.005 for the WW and IC fields, respectively). However, if only the shape but not the magnitude was considered, the low frequency peak for the IC is quite similar to that of the WW. Both spectra show a relatively broad peak with a family of four smaller peaks. This suggests that low frequency eddies impart a similar outer layer turbulent signature at both fields. The $u$ power spectrum for the IC, however, also contains a second and broader peak centered near $0.05 \mathrm{~Hz}\left(f z U^{-1}=0.02\right)$ not present at the WW. This may be due to differences in surface temperature and roughness between the two fields. Low frequency eddies are enhanced by local surface heating at the WW while they are decomposed continuously into smaller inner scale turbulence by the larger roughness elements of the IC. As a result, turbulent energy associated with the large eddies is redistributed across a range of smaller, high-frequency eddies.

The power spectra for the $v$ wind velocity component over the IC contains a low frequency peak located at approximately $0.01 \mathrm{~Hz}\left(f z U^{-1}=0.005\right)$. More interesting, however, is the distinct double-peak separated by a prominent gap from approximately $0.02 \mathrm{~Hz}\left(f z U^{-1}=0.008\right)$ to $0.05 \mathrm{~Hz}\left(f z U^{-1}=0.02\right)$. The presence of a well-defined gap surrounded by two prominent peaks suggests that the power spectrum for $v$ was composed of two distinct parts, one representing the low frequency contribution of advection and the other representing the higher frequency shear stress processes at the surface. Peltier et al. [24] predicted exactly this type of spectral division for the surface layer under convective conditions and McNaughton and Laubach [6] also showed a double peak in the $v$ spectra in a rice paddy at the base of convective inversion. In our case, the IC surface had a local stable boundary layer that bordered immediately adjacent to the WW field with strong convective conditions.

The $v$ power spectrum over the WW had a similar low frequency peak as described above. Although it was nearly two times larger for the WW than for the IC, the shape of the low frequency peak for the IC and WW fields were again remarkably similar. Additionally, similar to the $u$ velocity spectra, low frequency peaks in the $v$ velocity spectra also consisted of a relatively broad peak comprised of a family of four smaller peaks. Although the peaks associated with IC had shifted to slightly lower frequencies, this again suggests the persistence of low frequency events in this region. The second well-defined peak centered near $0.5 \mathrm{~Hz}$ $\left(f z U^{-1}=0.2\right)$ in the IC was not readily discernible in the spectra for the WW. This was not unexpected since the WW lacked a proper canopy structure.

The power spectra for the $w$ wind velocity at both fields were quite similar in the magnitude and location of the peaks (Fig. $8 \mathrm{c}-$ f). Additionally, there was considerable spectral broadening in the peak regions that could be attributable to (i) variability in the horizontal wind speed during intense advection in the afternoon hours and (ii) large scale turbulence motions $[6,46]$. Additionally, the spectra showed no discernible peak in the low frequency range; this result is consistent with conclusions of Zhang et al. [7] and McNaughton and Laubach [6] who found that near the surface large scale eddies tend to enhance horizontal motions in the low frequencies but suppress vertical motion in that range.

\subsection{Power spectra for scalar quantities}

The power spectra for the scalar quantities $T$ and $\rho_{v}$ are presented in Fig. 9 where the spectra were plotted on a fully logarithmic scale to enhance key relationships discussed herein. In general the spectra for $T$ and $\rho_{v}$ were nearly coincident in the frequency range from $0.3 \mathrm{~Hz}$ to $6 \mathrm{~Hz}$ for both the IC and WW except that the spectrum for $T$ over the WW was slightly offset to lower frequencies compared with the. This suggests that large eddy motions and strong local buoyancy forcings produced by strong surface heating at the WW enhanced large scale transport of heat. In the higher frequency range $(0.2-2 \mathrm{~Hz})$ all of the spectra had a slope near $-5 / 3$ demonstrating that inner-layer scaling was reasonably maintained $[14,15]$. This is in contrast to the intermediate frequencies from approximately $0.006-0.04 \mathrm{~Hz}$ which had a slope near -1 indicating that inner-layer scaling and outer-layer scaling were occurring simultaneously [6] .

In the lowest frequency range $(\sim 0.001$ to $0.006 \mathrm{~Hz})$, the power spectra for each scalar were not coincident. For example, the power spectrum for $\rho_{v}$ over the WW shows substantial contributions to the variance associated with large eddies with diameters in excess of $1 \mathrm{~km}$ while the power spectrum for $T$ shows little contribution from low frequency eddies. This may be a result of buoyancy forces from the WW surface having a greater influence than larger scale motions. The larger contribution of low frequencies observed in the power spectra of $\rho_{v}$ and $T$ over the IC was likely due to local and regional scale advection of warm, dry air across the moist IC surface. The additional heat and enhanced water vapor pressure deficit led to increased ET in excess of the available energy at the surface and, thereby, large and rapid changes in the scalar concentrations $\rho_{v}$ and $T$ over the IC surface. This observation was in agreement with other studies $[2,6,7]$ showing that large eddies can penetrate the SBL over a diverse range of surfaces and that these intrusions can result in large variations in scalar quantities.

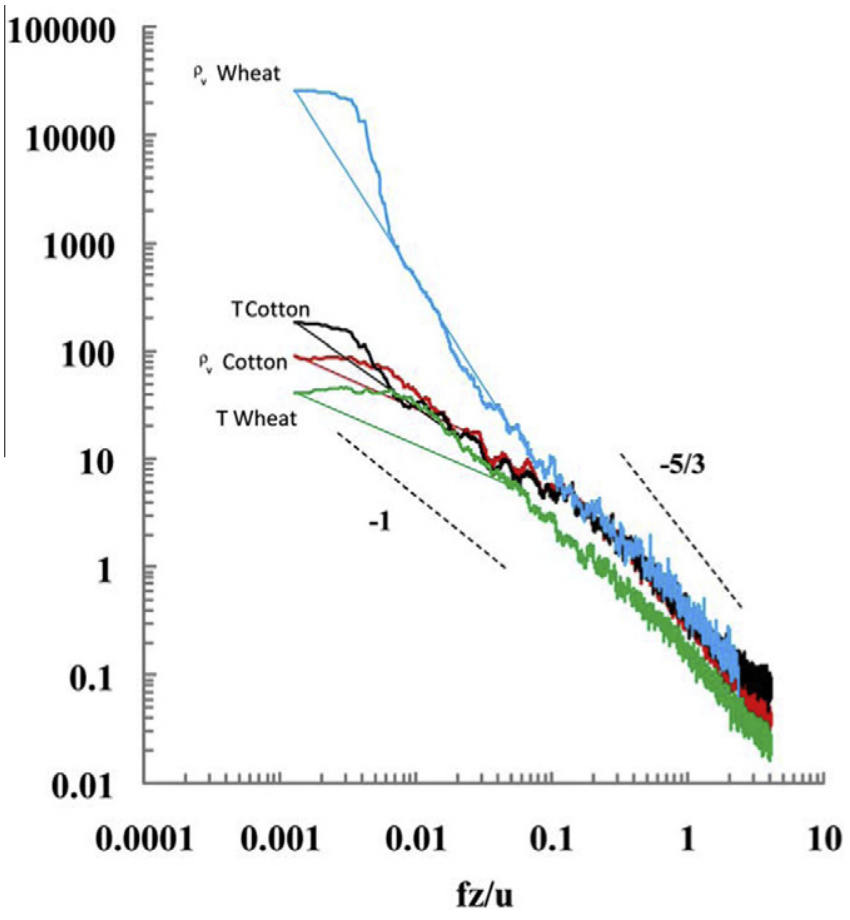

Fig. 9. Power spectra of air temperature $(T)$ and water vapor density $(\rho v)$ for August $4,2008,1600-1700$ CST are shown for the cotton and wheat stubble fields. 


\subsection{Cospectra}

The co-spectra for $u w, w T$ and $w \rho_{v}$ for the IC and WW are presented in Fig. 10a-f. In general, the co-spectra for momentum (Fig. 10a and d) at both sites shared a similar peak magnitude located at a frequency of about $0.3 \mathrm{~Hz}\left(f z U^{-1}=0.1\right.$ and $f z U^{-1}=0.11$ for the IC and WW, respectively) but differed in shape. The cospectrum for the WW had a more rounded shoulder in the lower frequency range from $0.03 \mathrm{~Hz}\left(f z U^{-1}=0.009\right)$ to $0.3 \mathrm{~Hz}\left(f z U^{-1}=0.1\right)$ and evidence of a strong low frequency updraft $(f<0.02$; $\left.f z U^{-1}<0.007\right)$ not observed in the co-spectrum for the IC (Fig. 10a and d). The updraft was likely due to increased buoyancy resulting from strong surface heating in the WW. Similar to the power spectra, significant jaggedness was observed at intermediate frequencies for these co-spectra (as well as the co-spectra for $w T$ and $w \rho_{v}$ ). This was attributed to the unsteadiness of the convective boundary layer and the resulting series of coherent and rapidly oscillating changes in the direction of vertical motion. It is posited that rapid variations in the co-spectrum of $u w$ for the IC represent sweeps and ejections that appear negligible individually, but, when integrated, represent rapid upward and downward eddy motions that transport considerable mass and energy between the surface and boundary layer. These results agree with those reported by others $[2,6-10,23,24]$.

Due to contrasting stability regimes, the co-spectra of $w T$ at IC and WW were distinct (Figs. 2d and $3 a$ and b). This was not altogether unexpected given the large negative and positive $H$ measured over the IC and WW, respectively (Fig. 10b-e). The inverted shape of the co-spectrum for $w T$ at the IC is indicative of the downward transport of $H$ while the positively directed shape of the co-spectrum for the WW demonstrates heat transport was away from the surface. The co-spectrum for $w T$ at the IC had a well-defined peak at approximately $0.05 \mathrm{~Hz}\left(f z U^{-1}=0.03\right)$ and showed clear contributions to the flux well into the lower frequencies. In contrast, the co-spectrum for $w T$ at the WW was less welldefined with a broader peak and multiple distinct sub-peaks. This indicates greater unsteadiness in the turbulent flow at the WW that was likely in response to the unstable conditions and additional buoyancy forces from the strong surface heating in that field. The stark differences in the transport of heat observed in the cospectra for $w T$ for two fields that are separated by less than $3 \mathrm{~m}$ suggests that not only were there physical differences field-tofield, there were differences in the partitioning of the surface energy budget as well.

The co-spectrum for $w \rho_{v}$ for the IC has a well-defined shape similar, albeit inverted, to the co-spectrum for $w T$. The peak at $0.3 \mathrm{~Hz}\left(f z U^{-1}=0.1\right)$ for the co-spectrum of $w \rho_{v}$ over the IC matches the location of the peak observed for $w T$, indicating that turbulent processes were well coupled to the SBL. In the case of the co-spectrum for $w \rho_{v}$ at the $\mathrm{WW}$ the most interesting feature is the clear discontinuity at approximately $0.01 \mathrm{~Hz}\left(f z U^{-1}=0.008\right)$. This discontinuity was also evident in the ogive plot (Fig. $6 \mathrm{~g}$ ) and was related to eddy scales in the range of $150-500 \mathrm{~m}$. The magnitude and sign of the contributions to the covariance from eddies of these scales again indicate that the low frequency eddies were decoupled from the local surface.

\subsection{Wavelet}

In order to better understand the underlying cause of the discontinuity observed in the ogive and conventional spectral analysis, a wavelet-based analysis was conducted. While the analysis
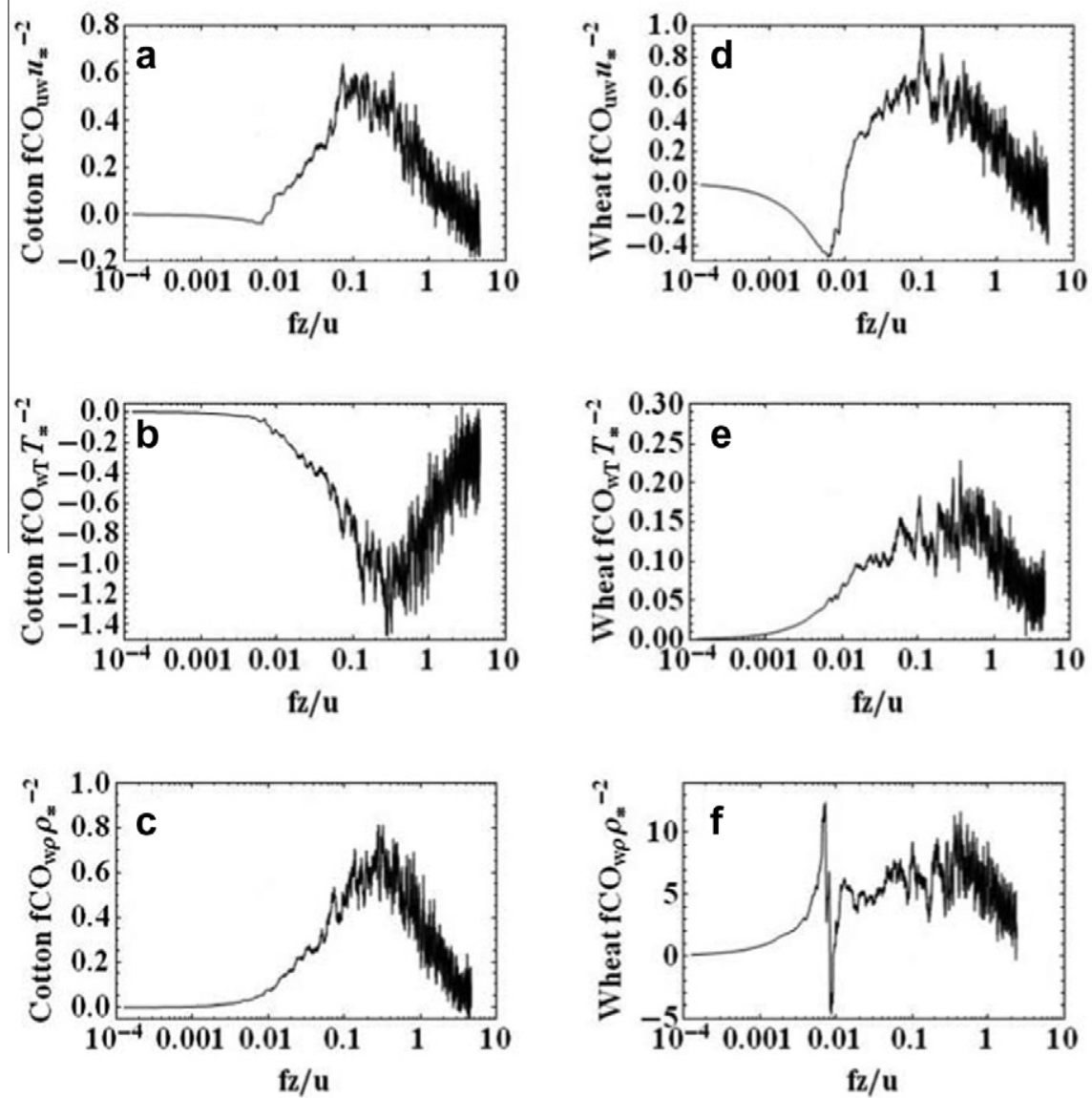

Fig. 10. Co-spectra for turbulent fluxes $u w, w T$ and $w \rho v$ for cotton (a-c) and wheat stubble (d-f) surfaces on August 4, 2008, 1600-1700 CST. 


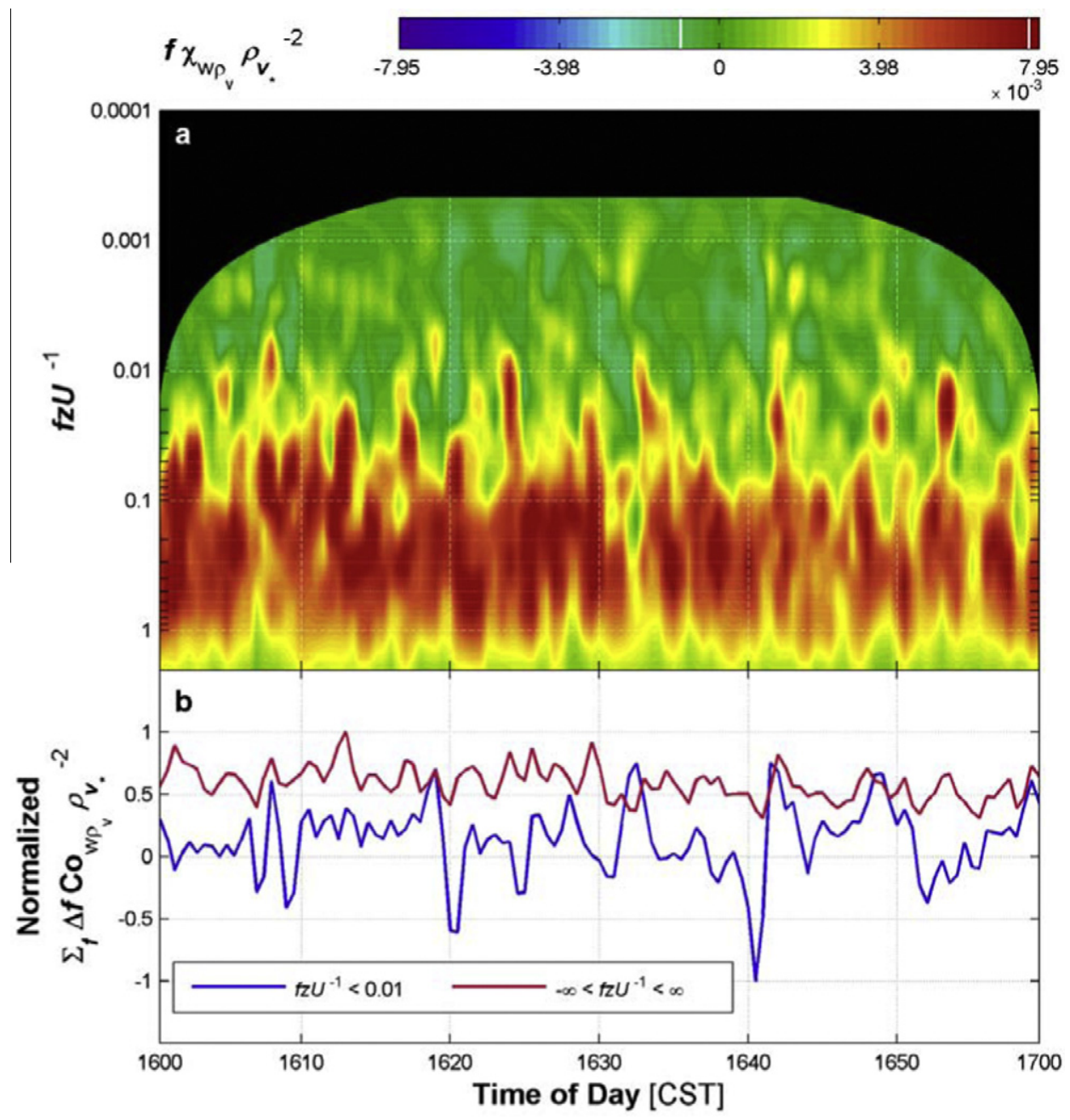

Fig. 11. The scalogram for $w \rho v$ (a) and its integration across frequencies (b) on August 4, 2008 1600-1700 CST are shown for the irrigated cotton field.

was conducted for the other scalar quantities as well, the focus here will be on $w \rho_{v}$ which produced typical results. As can be seen in Fig. 6, the ogive plots do not have the expected sigmoid shape with the cumulative $w \rho_{v}$. Rather, the ogive plot for the IC shows a well-defined gap where the cumulative $w \rho_{v}$ abruptly decreases by approximately $30 \%$ between frequencies from $0.03 \mathrm{~Hz}$ $\left(f z U^{-1}=0.014\right)$ to $0.02 \mathrm{~Hz}\left(f z U^{-1}=0.009\right)$. The cumulative $w \rho_{v}$ also declined for frequencies less than $0.01 \mathrm{~Hz}\left(f z U^{-1}=0.005\right)$. These features suggest that large water-laden eddies were penetrating the surface boundary layer and carrying moisture toward the surface.

Although it is not evident in the co-spectrum, the scalogram for $w \rho_{v}$ over the IC (Fig. 11) clearly shows that low-frequency transport occurred. There were a series of events occurring every 5-10 min when there was a small negative contribution to $\lambda E$ from large eddies. These downward directed events are counterbalanced by a series of weaker upward-directed events that occur about every $2-3 \mathrm{~min}$. This suggests that $\lambda E$ is influenced by processes that are occurring on two distinct time scales. On the shorter time scale, the moisture flux is enhanced by the local advection of warm dry air from the adjacent WW. On the longer timescale, moisture from sources well upwind of the study site is mixed into the SBL of the IC.

In the case of the $\mathrm{WW}$, the ogive plot for $w \rho_{v}$ increases smoothly as the frequency approached $0.03 \mathrm{~Hz}\left(f z_{m} U^{-1}=0.010\right)$ where it decreased precipitously and began oscillating erratically until the frequency reached approximately $0.01 \mathrm{~Hz}$. $\left(f z_{m} U^{-1}=0.003\right)$. At that point, it declined continuously with lower frequencies. At the same time, the co-spectrum indicated that the low-frequency contribution to the flux was negative (Fig. 10; Fig. 12c). In this case, the scalogram shows that the contribution to $\lambda E$ tended to be small but positive except for a few isolated low frequency events (Fig. 12a and b). Both the decline observed in the ogive plot and negative co-spectrum at low frequencies is due almost exclusively to a single event that occurred at approximately 1641 CST. The magnitude of this downward-direct event is greater than any contribution to $\lambda E$ directed away from surface. It is suggested that the event represents an intrusion of a particularly strong, large scale eddy that carried moister air from upwind sources.

\section{Summary and conclusions}

Using turbulence data collected over irrigated cotton and harvested wheat fields from 1600 to 1700 CST on August 4, 2008, characteristics of the near-surface turbulence were analyzed to better understand the role of strong advection on land-atmosphere exchange processes. This period was selected because strongly advective conditions were evident and the stability regimes of the two fields were distinct. The surface boundary layer over the IC was stable while the surface layer over the adjacent WW was unstable. 


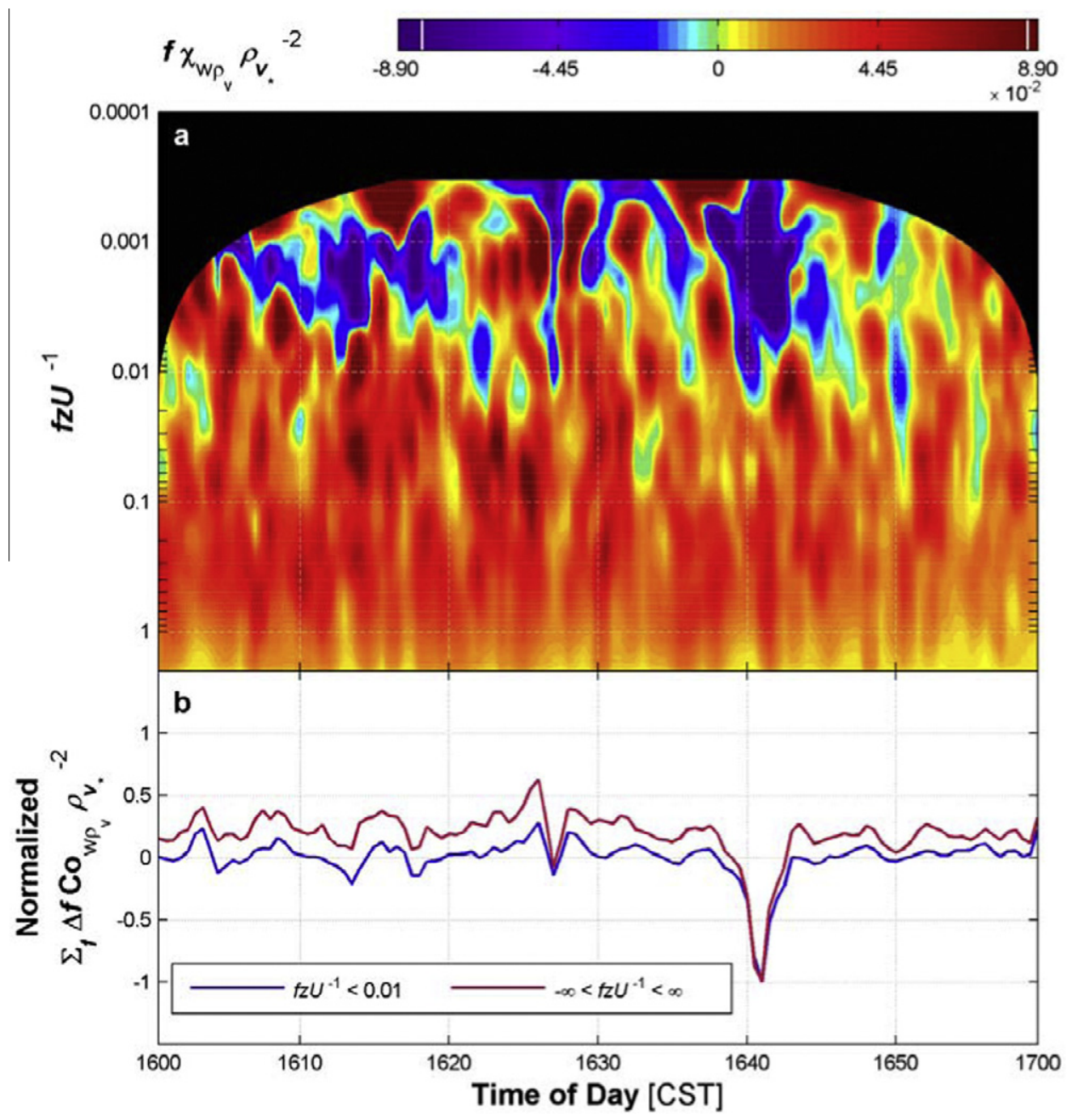

Fig. 12. The scalogram for $w \rho v$ (a) and its integration across frequencies (b) on August 4, 2008 1600-1700 CST are shown for the wheat stubble field.

In addition to showing a clear discontinuity between approximately 0.1 and $0.2 \mathrm{~Hz}$, the ogive plots for IC showed low-frequency reverse-sign contributions to the variance of $T$ and $\rho_{v}$. This suggests that warm dry air carried from the adjacent fields was entrained into the SBL of the IC. Evidence that the turbulence structure in the SBL was influenced by advection can also be found in the spectral analysis. Spectral analyses found features, particularly in the low frequency region of the spectra, not found in the well-established Kansas spectra [49] that were due to differences in spatial uniformity of the study environment; the Kansas study represented a homogeneous landscape while the BEAREX08 landscape was strongly heterogeneous. For example, the power spectra for the horizontal wind components showed significant low frequency contributions to the variance by eddies with diameters in excess of $0.5 \mathrm{~km}$. Moreover, the power spectrum for the $v$ wind velocity component measured over the IC exhibited a pronounced double-peak indicating two distinct regimes, one produced by local shear stress processes and the other by large scale eddy motions associated with advective processes. The co-spectrum for $w T$ over the WW showed the effects of both locally produced buoyancy and turbulent transport by the same large eddies.

One limitation of conventional spectral analysis is that results are a global time-averaged representation of turbulent processes across the period of interest. Expressed more simply, a spectral feature tells us that something happened during a period but not when it happened in the period. Wavelet analysis, presents the spectral response in a two-dimensional time-frequency space, which allows us to know when a specific event occurred and approximately how long it lasted. The wavelet analysis of $w \rho_{v}$ clearly demonstrates that the low-frequency contributions were intermittent and linked to distinct events. In the case of the IC, these events were characterized by the penetration of large scale (300-500 m) eddies into the SBL that significantly enhance $\lambda E$ by introducing warm dry air of local and regional origins. Infrequently, approximately every 5-10 min, larger eddies ( $>1 \mathrm{~km}$ ) of remote origins alter the SBL of the IC by introducing moisture (Figs. 6e, 11, 12). When this occurs, the low-frequency contribution to $\lambda E$ is directed toward the surface.

Overall, the analysis of the single hour during the afternoon of August 4, 2008 demonstrates that the turbulence structure of dryland and, in particular, irrigated croplands in semi-arid regions are strongly impacted by advective processes occurring across a range of spatial scales. Moreover, the strength and effect of these processes can vary substantially over time. As that happens, the advective enhancement of $\lambda E$, and thus the partitioning of the surface energy budget also changes. Therefore, understanding the complex chain of processes controlling advection and its influence on $\lambda E$ on local to regional scales is critical in order to improve our ability to measure and model the surface energy balance in semiarid environments. 


\section{References}

[1] House JI, Prentice JC, LeQuere C. Maximum impacts of future reforestation or deforestation on atmospheric $\mathrm{CO}_{2}$. Global Change Biol 2002;8:1047-52.

[2] Zermeno-Gonzalez A, Hipps LE. Downwind evolution of surface fluxes over a vegetated surface during local advection of heat and saturation deficit. J Hydrol 1997; 192:189-210.

[3] Hunsaker DJ, French AN, Clarke TR, El-Shikha DM. Water use, crop coefficients, and irrigation management criteria for camelina production in arid regions. Irrig Sci 2011:29:27-43.

[4] Monin AS, Obukhov AM. Basic laws of turbulent mixing in the ground layer of the atmosphere. Trans Geophys Inst Akad Nauk USSR 1954;151:163-87.

[5] Foken T. 50 years of the Monin-Obukhov similarity theory. Bound Layer Meteorol 2006;119:431-47.

[6] McNaughton KG, Laubach J. Power spectra and cospectra for wind and scalars in a disturbed surface layer at the base of an advective inversion. Bound Laye Meteorol 2000;96:143-85.

[7] Zhang Y, Liu H, Foken T, Williams QL, Mauder M, Thomas C. Coherent structures and flux contribution over an inhomogeneously irrigated cotton field. Theor Appl Climatol 2011;102:119-31.

[8] Smedman A-S. Observations of a multi-level turbulence structure in a very stable atmospheric boundary. Bound Layer Meteorol 1988;44:231-53.

[9] McNaughton KG. Turbulence structure of the unstable atmospheric surface layer and transition to the outer layer. Bound Layer Meteorol 2004;112:199-221.

[10] McNaughton KG. Attached eddies and production spectra in the atmospheric logarithmic layer. Bound Layer Meteorol 2004;111:1-18.

[11] McNaughton KG. On the kinetic energy budget of the unstable atmospheric surface layer. Bound Layer Meteorol 2006;118:83-107.

[12] McNaughton KG, Clement R, Moncrieff JB. Scaling properties of velocity and temperature spectra above the surface friction layer in a convective atmospheric boundary layer. Nonlinear Proc Geophys 2007;14:257-71.

[13] Smeets CJPP, Duynkerke PG, Vugts HF. Turbulence characteristics of the stable boundary layer over a mid-latitude glacier. Part 1: A combination of katabatic and large scale forcing. Bound Layer Meteorol 1998;87:117-45.

[14] Katul GG, Albertson JD, Cheng-T Hsieh, Conklin PS, Sigmon JT, Parlange MB, Knoerr KR. The inactive eddy motion and the large-scale turbulent pressure fluctuations in the dynamic sublayer. J Atmos Sci 1996;53:2512-24.

[15] Katul GG, Chu C-R. A theoretical and experimental investigation of energycontaining scales in the dynamic sub-layer of boundary-layer flows. Bound Layer Meteorol 1998;86:279-312.

[16] Högstrom U. Analysis of turbulence structure in the surface layer with a modified similarity formulation for neutral conditions. J Atmos Sci 1990;47:1949-72.

[17] Högstrom U, Bergström H. Organized turbulence structures in the near-neutral surface layer. J Atmos Sci 1996;53:2452-64.

[18] Högstrom U, Hunt JCR, Smedman A. Theory and measurements for turbulence spectra and variance in the atmospheric neutral surface layer. Bound layer Meteorol 2002;103:101-24.

[19] Andreas EL. Spectral measurements in a disturbed boundary layer over snow. J Atmos Sci 1987;44:1912-39.

[20] McNaughton KG, Brunet Y. Townsend's hypothesis, coherent structures and Monin-Obukhov similarity. Bound Layer Meteorol 2002;102:161-75.

[21] Baldocchi DD, Hicks BB, Meyers TP. Measuring biosphere-atmosphere exchanges of biologically related gases with micrometeorological methods. Ecology 1988;69(5):1331-40.

[22] Oncley SP, Foken T, Vogt R, Kohsiek W, DeBruin HAR, Bernhofer C, Christen A van Gorsel E, Grantz D, Feignwinter C, Lehner I, Liebethal C, Liu H, Mauder M, Pitacco A, Ribeiro L, Weidinger T. The energy balance experiment EBEX-2000. Part I: Overview and energy balance. Bound Layer Meteorol 2007;123:1-28.

[23] Prueger JH, Hipps LE, Cooper DI. Evaporation and the development of the local boundary layer over an irrigated surface in an arid region. Agric For Meteorol 1996;78:223-37.

[24] Peltier LJ, Wyngaard JC, Khanna S, Brasseur JG. Spectra in the unstable surface layer. J Atmos Sci 1996;53:49-61.

[25] Kader BA, Yaglom AM. Spectra and correlation functions of surface laye atmospheric turbulence in unstable stratification. In: Metais 0 , Lesieur $M$, editors. Turbulence and coherent structures. Norwel, MA: Kluwer Academic Publishers; 1991. p. 388-412.
[26] Alfieri JG, Niyogi D, Blanken PD, Chen F, LeMone MA, Mitchell KE, Ek MB, Kumar A. Estimation of the minimum canopy resistance for croplands and grasslands using data from the 2002 International $\mathrm{H}_{2} \mathrm{O}$ Project. Mon Weather Rev 2008;11:4453-69.

[27] Alfieri JG, Xioa X, Niyogi D, Pielke RA, Chen F, LeMone MA. Satellite based modeling of transpiration from grasslands in the Southern Great Plains, USA Global Planet Change 2008;67:78-86.

[28] Koniecki AD, Heilman JA. Water-use trends in the desert Southwest, 19502000: U.S. Geological Survey Scientific Investigations, Report 2004-5148; 2004. p. 32.

[29] Tanner CB, Thurtell, G. Anemoclinometer measurements of Reynolds stress and heat transport in the atmospheric surface layer. Research and Development Technical Report to US Army Electronic Command, ECOM 66-G22-F. Department of Soil Sciences, University of Wisconsin; 1969. p 199.

[30] Massman WJ. A simple method for estimating frequency response corrections for eddy covariance systems. Agri Forest Meteorol 2000;104:185-98.

[31] Webb EK, Pearman GI, Leuning R. Correction of flux measurements for density effects due to heat and water vapor transfer. Quart J Meteorol Soc 1980;106:85-100

[32] Foken T. The energy balance closure problem: an overview. Ecol Appl 2008;18(6):1351-67.

[33] Zhang Y, Liu H, Foken T, Williams QL, Shuhua L, Mauder M, Liebethal C. Turbulence spectra and cospectra under the influence of large eddies in the Energy Balance Experiment (EBEX). Bound Layer Meteorol 2010;136: 235-51.

[34] Hojstrup J. A statistical data screening procedure. Meas Sci Technol 1993;4:153-7.

[35] Kaimal JC, Finnigan JJ. Atmospheric boundary layer flows. New York: Oxford University Press; 1994. p. 289.

[36] Businger JA, Yaglom AM. Introduction to Obukhov's paper on turbulence in an atmosphere with a non-uniform temperature. Bound Layer Meteorol 1971; $2: 3-6$.

[37] Farge M. Wavelet transforms and their applications to turbulence. Ann Rev Fluid Mech 1992;24:395-457.

[38] Meyers SD, Kelly BG, O'Brien JJ. An introduction to wavelet analysis in oceanography and meteorology: with application to the dispersion of Yanai waves. Mon Weather Rev 1993;121:2858-66.

[39] Percival DB, Walden AT. Wavelet methods for time series analysis. Cambridge: Cambridge University Press; 2006. 594 pp.

[40] Terradellas E, Morales G, Cuxart J, Yague C. Wavelet methods: application to the study of the stable atmospheric boundary layer under non-stationary conditions. Dynam Atmos Ocean 2001;34:225-44.

[41] Torrence C, Compo G. A practical guide to wavelet analysis. Bull Am Meteorol Soc 1998;79:61-78.

[42] Thomas C, Mayer JC, Meixner FX, Foken T. Analysis of low-frequency turbulence above tall vegetation using a doppler sodar. Bound Layer Meteorol 2006:563-87.

[43] Chui CK. An introduction to wavelets. San Diego: Academic Press; 1992. p. 266.

[44] Brunet Y, Collineau S. Wavelet analysis of diurnal and nocturnal turbulence above a maize crop. In: Foufoula-Georgiou E, Kummar P, editors. Wavelet in geophysics. San Diego: Academic Press; 1994. p. 129-50.

[45] Brunt D. Notes on radiation in the atmosphere. Int Quart J Roy Meteorol Soc 1932;58:389-420.

[46] Fuchs M, Hadas A. The heat flux density in a non-homogeneous bare loessial soil. Bound Layer Meteorol 1972;3:191-200.

[47] Idso SB, Aase JK, Jackson RD. Net radiation-soil heat flux relations as influenced by soil water content variations. Bound Layer Meteorol 1975;9:113-22.

[48] Kaimal J, Wyngaard JC, Izumi Y, Coté OR. Spectral characteristics of surface layer turbulence. Quart J Roy Meteorol Soc 1972;98:563-89.

[49] Stull RB. An introduction to boundary layer meteorology. Dordrecht: Kluwer Academic Publishers; 1988. p. 666

[50] Mahrt L. Surface heterogeneity and vertical structure of the boundary layer. Bound Layer Meteorol 2000;96:33-62.

[51] Wyngaard JC. Lectures on the planetary boundary layer. In: Lilly DK, Gal-Chen T, editors. Mesoscale meteorology-theories, observations, and models. Reidel; 1983. p. 603-50.

[52] Brutsaert W. Land-surface water vapor and sensible heat flux: spatial variability, homogeneity, and measurement scales. Water Resour Res 1998; 34:2433-42. 